\title{
PEMBUATAN SERBUK U-6Zr DENGAN PENGKAYAAN URANIUM 19,75 \% UNTUK BAHAN BAKAR REAKTOR RISET
}

\author{
Masrukan K, Sungkono, Yanlinastuti, Tri Yulianto, Ridwan \\ Pusat Teknologi Bahan Bakar Nuklir - BATAN \\ Kawasan Puspiptek, Serpong, Tangerang Selatan, 15314 \\ e-mail: masrukan2006@yahoo.com
}

(Naskah diterima : 20-08-2015, Naskah direvisi: 15-09-2015, Naskah disetujui: 23-09-2015)

\begin{abstract}
ABSTRAK
PEMBUATAN SERBUK PADUAN U-6Zr DENGAN PENGKAYAAN URANIUM $19,75 \%$ UNTUK BAHAN BAKAR REAKTOR RISET. Telah dilakukan pembuatan serbuk paduan U-6Zr dengan pengkayaan $19,75 \%$ untuk bahan bakar reaktor riset. Pembuatan bahan bakar U-6Zr ini dalam rangka mencari bahan bakar baru yang mempunyai densitas tinggi untuk mengganti bahan bakar yang sudah ada $\mathrm{U}_{3} \mathrm{Si}_{2}-\mathrm{Al}$. Tujuan dari percobaan ini untuk mengetahui sifat-sifat serbuk paduan $\mathrm{U}-6 \mathrm{Zr}$ yang diperoleh dari proses hydriding-dehydriding sebagai kandidat bahan bakar reaktor riset. Serbuk yang diperoleh dari proses hydriding-dehydriding dikenai pengujian, diantaranya pungujian komposisi kimia, densitas, kandungan hidrogen, fasa dan sifat termal. Hasil pengujian komposisi kimia menunjukkan beberapa unsur seperti $\mathrm{Al}, \mathrm{Ca}, \mathrm{Cu}$, dan $\mathrm{Ni}$ melebihi batas yang diijinkan dimana masing-masing unsur terdapat sebesar 202,21 ppm; 214,05 ppm; 61,25 ppm dan 134,53 ppm. Pada pengujian diperolah densitas serbuk U-6Zr sebesar $13,58 \mathrm{~g} / \mathrm{cm}^{3}$ dan pada pengujian kandungan hidrogen sisa diperoleh kandungan hidrogen sebesar $0,16 \%$. Untuk pengujian fasa, diperoleh fasa $\alpha U$ dan $\delta U$, sedangkan pada pengujian sifat termal yakni transformasi temperatur terdapat dua puncak yakni puncak pertama terjadi pada temperatur 274 hingga $311^{\circ} \mathrm{C}$ dan puncak kedua terjadi pada temperatur 493 hingga $527^{\circ} \mathrm{C}$. Puncak pertama terjadi reaksi endotermik dengan menyerap panas sebesar $\Delta \mathrm{H}=6,23 \mathrm{cal} / \mathrm{g}$ tetapi tidak terbentuk fasa baru, sedangkan puncak kedua terjadi reaksi eksotermik dengan mengeluarkan panas sebesar $\Delta \mathrm{H}=-9.34 \mathrm{cal} / \mathrm{g}$ dan terbentuk fasa $\alpha \mathrm{Zr}$. Sementara itu, dari pengujian kapasitas panas pada temperatur 34 hingga $75^{\circ} \mathrm{C}$, terjadinya penurunan nilai kapasitas panas yang disertai dengan penyerapan panas. Pada temperatur yang lebih tinggi hingga temperatur $437^{\circ} \mathrm{C}$ nilai kapasitas panas menjadi lebih kecil disertai pengeluaran panas. Reaksi termokimia antara $\mathrm{Zr}$ dengan hidrogen sisa menunjukkan terbentuknya fasa $\alpha \mathrm{Zr}$ yang diindikasikan oleh reaksi eksotermik dengan mengeluarkan panas sebesar $\Delta \mathrm{H}=9,3449 \mathrm{cal} / \mathrm{g}$. Dari hasil analisis dapat diketahui bahwa paduan U-6Zr tersebut dapat digunakan sebagai bahan bakar pengganti untuk reaktor riset.
\end{abstract}

Kata kunci: Serbuk U-6Zr, pengkayaan U 19,75\%, bahan bakar, reaktor riset. 


\section{ABSTRACT}

MAKING OF U-GZr ALLOY POWDER WTH URANIUM ENRICHMENT OF $19.75 \%$ FOR RESEARCH REACTOR FUEL. Making U-6Zr alloy powder with enrichment of $19.75 \%$ for a research reactor fuel has been done. Making of U-6Zr fuel in order to find new fuels that have a high density to replace the existing fuel $\mathrm{U}_{3} \mathrm{Si}_{2}-\mathrm{Al}$. The purpose of this experiment was to determine the properties of $U-6 Z r$ alloy powder obtained from the hydriding-dehydriding process as a candidate research reactor fuel. Initially was made U-6Zr ingot by melting $U$ and $Z r$ metals using electric arc melting furnace. U-6Zr ingots were found then cut into pieces and put into hydridingdehydriding equipment that operates at pressures 14,46054 psi and hydriding temperatures of $350^{\circ} \mathrm{C}$. Ingots that out of the hydriding-dehydriding equipment becomes brittle then was crushed so becomes powder. Powder that obtained subjected to the test, including chemical composition testing, density, hydrogen content, phase and thermal properties. The results testing show that chemical composition of some elements such as $\mathrm{Al}, \mathrm{Ca}, \mathrm{Cu}$, and Ni exceeded the permitted limit, each of which contained elements of 202.21 ppm, 214.05 ppm, 61.25 ppm, and 134.53 ppm. On testing the density obtained that U-6Zr powder density of $13.57 \mathrm{~g} / \mathrm{cc}$ and the testing of hydrogen residual content obtained hydrogen residual content of $0.16 \%$. For the testing phase were obtained the $\alpha U$ and $\delta U$ phases, while in testing of the transformation temperature, there are two peaks, the first peak occurs at a temperature of 274 to $311{ }^{\circ} \mathrm{C}$ and a second peak occurs at a temperature of 493 to $527^{\circ} \mathrm{C}$. The first peak occurs endothermic reaction by absorbing heat of $6.23 \mathrm{cal} / \mathrm{g}$ but not formed a new phase, while the second peak occurs exotermic reaction with brought out heat of $-9.34 \mathrm{cal} / \mathrm{g}$ and formed $\alpha \mathrm{Zr}$ phase. Meanwhile, the heat capacity of the test at temperature of 34 to $75{ }^{\circ} \mathrm{C}$, the decrease in the value of the heat capacity accompanied heat absorption. At higher temperatures up to $437^{\circ} \mathrm{C}$, heat capacity value becomes negative and accompanied by heat expenditure. It can be concluded that the alloy the U-6Zr when viewed from the chemical composition can still be used for fuel research reactor. Residual hydrogen still found in small quantities in the U-6Zr powder that can be eliminated by heating for longer. Reaction between $\mathrm{Zr}$ with residual hydrogen to form the $\alpha Z$ phase is accompanied exothermic reaction with brought out heat of $93449 \mathrm{cal} / \mathrm{g}$.

Keywords: U-6Zr powder, U enrichment of $19.75 \%$, fuel, research reactor. 


\section{PENDAHULUAN}

Pengembangan bahan bakar terus diupayakan dalam rangka mencari bahan bakar jenis baru yang mempunyai densitas lebih tinggi dari bahan bakar $\mathrm{U}_{3} \mathrm{Si}_{2}-\mathrm{Al}$ yang digunakan pada saat ini. Beberapa jenis bahan bakar sedang dicoba dikembangkan diantaranya paduan U-Mo dan U-Zr. Percobaan pendahuluan pembuatan bahan bakar berbasis paduan $\mathrm{U}-\mathrm{Zr}$ telah dilakukan dimulai dari pmbuatan paduan U-Zr yang dikenai perlakuan panas dan dikarakterisasi, serbuk $\mathrm{U}-\mathrm{Zr}$ yang dikarakterisasi hingga pembuatan pelat elemen bakar (PEB) mini menggunakan uranium deplesi dan dikarakterisasi ${ }^{11]}$. Pembuatan PEB mini telah dilakukan pada tingkat muat $U$ sebesar $5,2 \mathrm{gU} / \mathrm{cm}^{3}$ dengan hasil yang cukup baik. Penelitian lanjutan telah dilakukan untuk membuat PEB pada tingkat muat uranium yang sama tetapi menggunakan uranium diperkaya sebesar $19,75 \%$. PEB tersebut direncanakan akan dimasukkan ke dalam reaktor RSG Siwabessy untuk menjalani uji iradiasi. Untuk membuat serbuk bahan bakar U-6Zr yang bersifat keras dan ulet tidak bisa dilakkan dengan cara konvensional misalnya cara milling sehingga diperlukan cara lain yaitu dengan cara hydriding-dehydriding. Sebenarnya ada beberapa cara yang dapat digunakan untuk membuat material ulet seperti $\mathrm{U}-\mathrm{Zr}$, misalnya mechanical crusching (milling, grinding atau menambahkan unsur pemadu untuk menambah kerapuhan, cryogenic mechanical crushing), hydride-dehydride dan proses atomisasi. Cara atomisasi telah dipatenkan oleh Korea pada tahun 2001 (Korean Atomic Energy Research Institute) ${ }^{[2,3]}$. Cara atomisasi menghasilkan partikel berbentuk bulat (spheric), dimana bentuk spheric menyulitkan untuk dibuat pelat bahan bakar yang tipis. Hal ini disebabkan pada saat dilakukan pengerolan serbuk yang mempunyai bentuk spheric maka serbuk akan lari menuju ke arah dinding selain ke arah pengerolan sehingga menjadi lebih tebal. Selain itu, cara atomisasi juga dapat menghasilkan serbuk yang tidak homogen. Dari kenyataan tersebut maka perlu dilakukan percobaan dengan cara lain untuk memperoleh serbuk dari material yang ulet, yaitu dengan cara hydriding dehydriding (HD). Dalam cara hydriding-dehydriding, ingot U-6Zr yang bersifat keras dan ulet akan menjadi rapuh karena adanya hidrogen yang masuk ke dalam ingot U-6Zr. Hidrogen yang masuk ke dalam ingot $\mathrm{U}-6 \mathrm{Zr}$ akan membentuk hidrida U-6ZrHx berbentuk amorf. Apabila hidrida U6ZrHx yang amorf tersebut dipanaskan lagi (dehydriding) maka hidrida $\mathrm{U}-6 \mathrm{ZrHx}$ yang amorf melepaskan hidrogen sehingga tersisa amorf U-Zr. Pelepasan hidrogen (dehydriding) dapat dilakukan dengan dua cara. Cara yang pertama, ingot yang rapuh hasil hydriding dihancurkan terlebih dahulu sehingga menjadi serbuk U-Zr kemudian dilakukan dehydriding, sedangkan cara yang kedua langsung dilakukan proses dehydriding terhadap ingot hasil hydriding. Cara yang pertama terdapat kesulitan dalam pelaksaaannya dan harus dilakukan dengan sangat hati-hati karena U-6Zr dalam bentuk serbuk mudah teroksidasi sehingga diperlukan penanganan khusus. Oleh karena itu dalam pelaksanaan pembuatan U-6Zr lebih mudah dilakukan menggunakan cara yang kedua yaitu langsung dilakukan dehydriding setelah proses hydriding. Selain itu, untuk membuat material yang rapuh juga dapat dilakukan dengan beberapa gas selain hidrogen yakni dengan gas nitrogen. Namun, dalam pelaksanaannya tidak digunakan gas nitrogen karena ukuran atom gas nitrogen terlalu besar sehingga menyulitkan terjadinya interdifusi dalam material. Oleh karena itu pelaksanaan pembuatan material yang mudah rapuh digunakan gas hidrogen agar proses difusi mudah terjadi. Namun, yang perlu diperhatikan bahwa penggunaan gas hidrogen memerlukan penanganan hati-hati karena hidrogen mudah berreaksi dengan oksigen 
dalam perbandingan tertentu yang dapat mengakibatkan terjadinya letupan.

Paduan U-Zr amorf hasil hydriding tersebut bersifat rapuh sehingga mudah dihancurkan dengan cara milling menjadi serbuk. Beberapa parameter yang harus diperhatikan dalam proses hydridingdehydriding adalah jumlah gas hidrogen yang digunakan (flow rate), kemurnian gas hidrogen, luas permukaan material yang dikenai proses hydriding-dehydriding (ingot U-6Zr), dan temperatur operasi. Jumlah gas hidrogen dapat dilihat melalui tekanan gas yang masuk dan dapat diketahu terjadinya penyerapan gas oleh material. Kemurnian gas yang digunakan sebaiknya mempunyai kemurnian yang tinggi yaitu Ultra Hight Purity (UHP), karena dengan menggunakan gas UHP maka dapat dihindari kontaminan di dalam hasil. Luas permukaan material yang dikenai proses hydriding-dehydriding akan mempengaruhi hasil yang diperoleh karena semakin luas permukaan bidang sentuh dari material maka semakin banyak kontak gas hidrogen dapat terjadi sehingga interdifusi antara hidrogen dengan $\mathrm{U}-6 \mathrm{Zr}$ dapat berlangsung dan semakin baik hasil yang diperoleh. Beberapa keunggulan yang diperoleh apabila menggunakan cara hydriding-dehydriding antara lain adalah: tidak diperlukan peralatan yang rumit dan energi yang besar, prosesnya sederhana, dapat menghasilkan bentuk partikel granular dalam rentang ukuran yang luas ${ }^{[4]}$. Serbuk U- 6Zr yang diperoleh apabila akan dibuat menjadi inti elemen bakar (IEB) maka serbuk tersebut harus dicampur dengan matriks aluminium, selanjutnya IEB dapat dibuat menjadi pelat elemen bakar (PEB) dengan cara dirol panas dan dirol dingin serta dikarakterisasi sesuai persyaratan PEB.

\section{METODOLOGI}

Dalam pembuatan serbuk U-6Zr dengan pengkayaan 19,75 \% beberapa pekerjaan yang dilakukan antara lain meliputi: pembuatan ingot, pembuatan serbuk, pengujian ingot dan serbuk. Adapun langkah-langkah percobaan adalah sebagai berikut:

\section{a. Pembuatan ingot U-6Zr}

Dalam membuat ingot U-6Zr, logam $U$ dan $\mathrm{Zr}$ dilebur dimana masing-masing logam mempunai komposisi $94 \% \mathrm{U}(9,4 \mathrm{~g})$ dan $6 \% \mathrm{Zr}(0,6 \mathrm{~g})$ dengan berat total lebih kurang $10 \mathrm{~g}$. Kedua logam $\mathrm{U}$ dan $\mathrm{Zr}$ dimasukkan ke dalam tungku peleburan untuk selanjutnya dilakukan proses peleburan. Cara yang digunakan untuk melakukan peleburan adalah cara busur lisrik. Dalam tungku busur listrik (ArC furnace) dilengkapi dengan sistem pendingin menggunakan air. Tungku peleburan dioperasikan pada arus sebesar $150 \mathrm{~A}$ dan selama proses peleburan berlangsung dialirkan gas Ar untuk mencegah terjadinya oksidasi. Sampel yang dilebur dibolak-balik sebanyak 5 (lima) kali agar tercapai hasil yang homogen. Hasil peleburan diperoleh berupa ingot dengan bentuk lingkaran berdiameter lebih kurang $15 \mathrm{~mm}$ dan ketebalan pada bagian tengah lebih kurang $2 \mathrm{~mm}$ serta pada bagian pinggir $1 \mathrm{~mm}$, selanjutnya ingot dipotong tipis hingga berukuran $10 \times 2 \times 1 \mathrm{~mm}$ untuk dikenai proses hydriding-dehydriding.

\section{b. Pembuatan serbuk U-6Zr}

Pada proses hydriding, ingot $\mathrm{U}-6 \mathrm{Zr}$ dipotong-potong kemudian dimasukkan ke dalam wadah yang terbuat dari bahan gelas dan dimasukkan ke dalam tabung retort di dalam peralatan hydriding seperti yang ditunjukkan pada Gambar 1. Hydriding dimulai dengan memanaskan sampel hingga temperatur $450{ }^{\circ} \mathrm{C}$ ditahan selama 10 jam. Proses hydriding dilakukan dengan cara menghidupkan pompa vakum dan membuka valve sehingga tekanan vakum mencapai 14,46 psi. Semua sampel dipanaskan pada temperatur $350{ }^{\circ} \mathrm{C}$ selama 1 jam, setelah itu pompa vakum dimatikan. Gas hidrogen dialirkan/ diisikan ke dalam reservoir dengan tekanan awal 14,80 s/d 14,81 psi, kemudian dialirkan ke tabung retort yang berisi sampel 
dan setiap 15 menit diambil data penyerapan dari pembacaan pada manometer. Pengisian gas hidrogen dilakukan kembali (siklus II) ketika tekanan gas sudah berkurang, dan dilakukan pengisian berikutnya (siklus III) hingga pengamatan pada sampel sudah dianggap rapuh. Tahapan akhir proses ini, tungku dimatikan dan temperatur diturunkan hingga temperatur kamar. Dalam proses hydriding ini beberapa parameter perlu mendapatkan perhatian, diantaranya adalah: tekanan, kemurnian gas hidrogen, tempe-ratur operasi, luas permukaan material yang dikenai hydriding. Tekanan gas berhubungan dengan jumlah gas yang digunakan selama proses proses hydriding berlangsung dan dapat diketahui terjadinya penyerapan gas hidrogen oleh material. Kemurnian gas yang digunakan sebaiknya gas dengan kemurnian tinggi yaitu Ultra Hight Purity (UHP), karena dengan menggunakan gas UHP maka dapat dihindari kontaminan di dalam hasil. Temperatur operasi perlu diperhatikan karena semakin tinggi temperatur operasi maka pergerakan atom-atom baik atom hidrogen maupun material $\mathrm{U}-6 \mathrm{Zr}$ akan semakin banyak sehingga tumbukan antara atom hidrogen dan material semakin meningkat. Akibat tumbukan menyebabkan interdifusi atom semakin banyak sehingga hasil hydriding yang diperoleh semakin baik. Luas permukaan material yang dikenai hydridingdehydriding akan mempengaruhi hasil yang diperoleh karena permukaan bidang sentuh dari material semakin luas maka semakin banyak kontak gas hidrogen dengan material $\mathrm{U}-6 \mathrm{Zr}$ terjadi sehingga interdifusi antara hidrogen dengan $\mathrm{U}-6 \mathrm{Zr}$ dapat berlangsung dan semakin baik hasil yang diperoleh. Setelah proses hydriding selesai selanjutnya dilakukan dehydriding untuk mengusir gas hidrogen dengan cara melakukan pemanasan kembali hingga temperatur $450{ }^{\circ} \mathrm{C}$ sehingga yang tersisa adalah ingot $\mathrm{U}-\mathrm{Zr}$ yang rapuh dan mudah dihancurkan menjadi serbuk. Pelaksanaan dehydriding dilakukan langsung pada saat selesai proses hydriding, hal ini untuk memudahkan proses penanganan dan menghindari oksidasi dari udara.

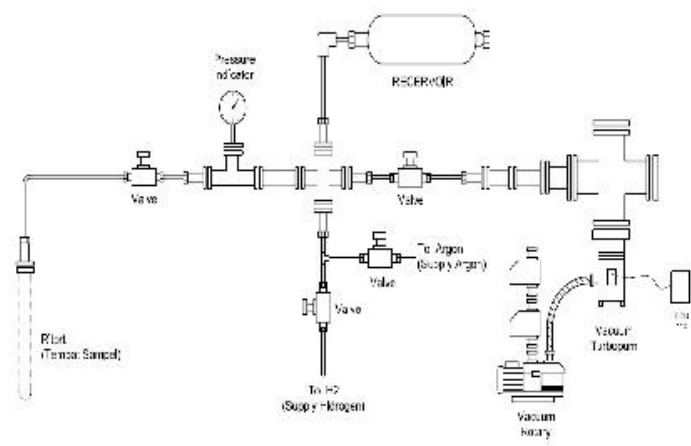

Gambar 1. Skema sistim peralatan hydriding dehydriding.

\section{c. Pengujian-pengujian}

Serbuk U-6Zr yang diperoleh dari proses hydriding dehydriding selanjutnya dikenai beberapa pengujian, diantaranya: komposisi kimia, densitas, kandungan hidrogen, fasa, sifat termal. Pengujian komposisi kimia dilakukan menggunakan UV-VIS dan AAS. Pengujian kimia dimaksudkan untuk mengetahui komposisi penyusun paduan dan pengotornya. Pengujian densitas dilakukan dengan menggunakan piknometer dalam suasana gas helium. Nilai densitas penting artinya karena akan menentukan jumlah uranium yang dapat ditambahkan ke dalam bahan bakar. Untuk menentukan jumlah gas hidrogen di dalam bahan bakar dilakukan dengan peralatan Hydrogen Analyser. Di dalam bahan bakar, kandungan hidrogen serendah-rendahnya, sedangkan untuk menentukan jenis fasa yang ada di dalam serbuk hasil hydriding digunakan peralatan difraksi sinar-X (XRD). Hasil pengujian difraksi sinar- $X$ diperoleh jenis fasa yang dapat dilihat dari indeks Miller yang muncul. Fasa yang ada di dalam serbuk paduan akan mempengaruhi karakteristik serbuk paduan bahan bakar. Sementara itu, analisis sifat termal dilakukan menggunakan Differential Scanning Calorimetry (DSC). Hasil pengujian dengan DSC dapat mengetahui jumlah panas yang dilepas 
maupun yang diserap oleh serbuk bahan bakar selama bahan bakar digunakan.

\section{HASIL DAN PEMBAHASAN}

\section{a. Uji komposisi kimia}

Hasil uji komposisi kimia dari logam $\mathrm{U}, \mathrm{Zr}$ dan serbuk paduan U-6Zr ditampilkan dalam Tabel 1. Hasil analisis komposisi kimia dengan menggunakan AAS dan UVVIS menunjukkan sebagian besar unsurunsur yang terdapat di dalam serbuk U-6Zr masih memenuhi persyaratan sebagai bahan bakar nuklir. Beberapa unsur yang melebihi persyaratan diantarnya unsur Al, $\mathrm{Ca}, \mathrm{Cu}$ dan $\mathrm{Ni}$, dimana masing-masing unsur tersebut diperoleh dengan kandungan sebesar 202,2097 ppm; 214,0545 ppm; 61,2538 ppm dan 134,5324 ppm.

Tabel 1. Hasil pengujian komposisi kimia (pengotor) di dalam serbuk U-6Zr.

\begin{tabular}{|c|c|c|c|}
\hline No & Unsur & $\begin{array}{l}\text { Maksimum } \\
\text { ppm }\end{array}$ & Hasil analisis (ppm) \\
\hline 1 & $\mathrm{Ag}$ & 1.0 & 0.77 \\
\hline 2 & $\mathrm{Al}$ & 50,0 & 202,21 \\
\hline 3 & $\mathrm{~B}$ & 0,3 & $0,30^{*}$ \\
\hline 4 & C & 100,0 & $100^{\circ}$ \\
\hline 5 & $\mathrm{Ca}$ & 50,0 & 214.05 \\
\hline 6 & $\mathrm{Cd}$ & 0,2 & 0,07 \\
\hline 7 & $\mathrm{Cl}$ & 15,0 & $15,00^{*}$ \\
\hline 8 & Co & 75,0 & 2,30 \\
\hline 9 & $\mathrm{Cr}^{*}$ & 100,0 & 42,55 \\
\hline 10 & $\mathrm{Cu}$ & 20,00 & 61,25 \\
\hline 11 & $\mathrm{~F}$ & 10,00 & $* *$ \\
\hline 12 & $\mathrm{Fe}^{\lambda}$ & 100,00 & 71,48 \\
\hline 13 & $\mathrm{Mg}$ & 50,00 & 12,95 \\
\hline 14 & $\mathrm{Mn}$ & 10,00 & 47,71 \\
\hline 15 & Mo & 50,00 & 3,58 \\
\hline 16 & $\mathrm{H}^{*}$ & 80,00 & ${ }^{x \times}$ \\
\hline 17 & $\mathrm{Ni}$ & 30,00 & 134,53 \\
\hline 18 & $\mathrm{~Pb}$ & 60,00 & 8,47 \\
\hline 19 & $\mathrm{Si}$ & 60,00 & 48,82 \\
\hline 20 & Sn & 50,00 & 7,71 \\
\hline 21 & $\mathrm{~V}$ & 5,00 & 81,706 \\
\hline 22 & $\mathrm{Zn}$ & 100.00 & 22.65 \\
\hline 23 & Dy & 0,15 & $\star *$ \\
\hline 24 & $\mathrm{Gd}$ & 0,50 & ** \\
\hline 25 & $\begin{array}{l}\mathrm{Dy}^{*}+\left[\mathrm{u}^{*}+\mathrm{Gd}^{*}\right. \\
+\mathrm{Sm}^{*}\end{array}$ & 0,60 & ** \\
\hline & \multicolumn{2}{|c|}{ Jumlah } & 1108,13 \\
\hline
\end{tabular}

Dari keempat unsur yang melebihi batas persyaratan tersebut tidak ada unsur yang mempunyai nilai tampang lintang serapan neutron mikroskopik tinggi, karena apabila terdapat unsur yang mempunyai nilai tampang lintang mikros-kopik tinggi dalam jumlah yang tinggi dikhawatirkan operasi reaktor akan terhenti karena menjadi tidak kritis[5]. Namun, apabila unsur-unsur impuritas tersebut dijumlahkan maka jumlah keseluruhan unsur tidak melampaui batas maksimum yang diijinkan yaitu sebesar $2 \%$ (jumlah keseluruhan 0,1108\%). Komposisi unsur di dalam bahan bakar mempunyai peranan yang penting karena keberadaan unsur dapat mempe-ngaruhi sifat-sifat paduan logam misalnya sifat mekanaik, ketahanan korosi, sifat termal dan lain-lain. Hal ini disebabkan unsur-unsur di dalam paduan dalam jumlah tertentu dapat membentuk senyawa maupun fasa kedua.

\section{b. Densitas}

Hasil uji densitas serbuk ditampilkan dalam Tabel 2. Tabel 2 merupakan pengujian yang dilakukan sebanyak lima belas kali. Dalam pelaksanaan setiap kali percobaan digunakan volume serbuk ratarata sebesar 1,6 $\mathrm{cm}^{3}$ dan menghasilkan densitas serbuk U-6Zr rata-rata sebesar $13,5778 \mathrm{gU} / \mathrm{cm}^{3}$. Hasil tersebut masih dibawah densitas teoritisnya yakni sebesar $18,114 \mathrm{gU} / \mathrm{cm}^{3}$. Hasil pengukuran densitas yang diperoleh lebih rendah, hal ini disebabkan masih adanya impuritas dalam serbuk sehingga mempengaruhi nilai densitas yang diperoleh. Nilai densitas sangat penting diketahui dalam pembuatan elemen bakar karena nilai densitas akan menentukan jumlah aluminium yang ditambahkan sebagai matriks dalam bahan bakar nuklir. Densitas bahan bakar diharapkan sebesar-besarnya agar jumlah uranium yang dapat dimasukkan ke dalam bahan bakar sebesar-besarnya setiap satuan volume ${ }^{[6]}$. 
Tabel 2. Hasil pengujian densitas U-6Zr

\begin{tabular}{l|l|l|}
\hline No & $\begin{array}{l}\text { Volume } \\
(\mathrm{cc})\end{array}$ & Densitas $(\mathrm{g} / \mathrm{cc})$ \\
1 & 1,6320 & 13,63 \\
\hline 2 & 1,6304 & 13,65 \\
\hline 3 & 1,6332 & 13,62 \\
4 & 1,6343 & 13,61 \\
\hline 5 & 1,6340 & 13,62 \\
\hline 6 & 1,6349 & 13,61 \\
\hline 7 & 1,6361 & 13,60 \\
8 & 1,6346 & 13,61 \\
\hline 9 & 1,6349 & 13,60 \\
\hline 10 & 1,6348 & 13,61 \\
11 & 1,6358 & 13,60 \\
12 & 1,6371 & 13,59 \\
\hline 13 & 1,6388 & 13,57 \\
\hline 14 & 1,6392 & 13,57 \\
15 & 1,6398 & 13,56 \\
\hline & Rerata & 13,58 \\
\hline
\end{tabular}

\section{c. Kandungan hidrogen}

Uji kandungan hidrogen bertujuan untuk memastikan ada tidaknya gas hidrogen yang masih tersisa di dalam serbuk $\mathrm{U}-6 \mathrm{Zr}$ yang diperoleh melalui proses hydriding-dehydriding. Kandungan hidrogen di dalam serbuk U-6Zr yang akan digunakan untuk bahan bakar reaktor riset harus dihilangkan. Hidrogen di dalam serbuk bahan bakar dispersi tidak diperlukan karena reaktor beroperasi pada temperatur yang rendah sementara hidrogen yang terikat dengan $\mathrm{Zr}$ sebagai hidrida dapat mempertahankan bahan bakar pada temperatur tinggi. Selain itu, hidrogen yang tersisa juga akan menurunkan nilai densitas dari bahan bakar. Hidrogen yang tersisa akan membentuk senyawa hidrida $\mathrm{ZrH}_{\mathrm{x}}$ $\left(\mathrm{U}-6 \mathrm{ZrH}_{\mathrm{x}}\right)$, dimana densitas $\mathrm{U}-6 \mathrm{ZrH}_{\mathrm{x}}$ lebih rendah dibandingkan densitas serbuk U-6Zr. Memperhatikan hasil uji kandungan hidrogen seperti tertera di dalam Tabel 3, terlihat bahwa kandungan hidrogen rata-rata di dalam serbuk U-6Zr sebesar 1607,78 ppm atau sebesar 0,16\%. Hasil tersebut sangat kecil, sehingga tidak memungkinkan dapat membentuk senyawa $\mathrm{U}-6 \mathrm{ZrHx}$ dan keberadaan hidrogen sisa tidak mempengaruhi sifat-sifat $\mathrm{U}-6 \mathrm{Zr}$ yang terbentuk.

Tabel 3. Hasil uji kandungan hidrogen di dalam U-6Zr

\begin{tabular}{|c|c|c|c|c|}
\hline No & Kode Sampel & $\mathrm{ppm} \mathrm{O}_{2}$ & $\mathrm{ppm} \mathrm{H}_{2}$ & $\mathrm{mg}$ \\
\hline 1 & blanko 1 & 13,11 & 5,36 & $1.060,70$ \\
\hline 2 & blanko 2 & 11,82 & 4,57 & $1.063,00$ \\
\hline 3 & Rerata blanko & 12,46 & 12,47 & 4,97 \\
\hline 4 & U-6Zr alloy serbuk (1) & 50,10 & 1945,83 & 174,80 \\
\hline 5 & U-6Zr alloy serbuk (2) & 40,66 & 1915,96 & 154,00 \\
\hline 6 & Rerata Hasil & 45,38 & 1930,89 & \\
\hline 7 & U-6Zr alloy granular (1) & 176,07 & 1528,34 & 58,20 \\
\hline 8 & U-6Zr alloy granular (2) & 243,17 & 1364,13 & 51,40 \\
\hline 9 & Rerata Hasil & 209,62 & 1446,22 & \\
\hline
\end{tabular}

\section{d. Uji XRD (Fasa)}

Hasil uji fasa ingot U-6Zr menggunakan XRD ditampilkan dalam Gambar 1. Dari Gambar 1 memperlihatkan bahwa di dalam $\mathrm{U}-6 \mathrm{Zr}$ terdapat fasa $\alpha \mathrm{U}$ dan $\delta U$. Fasa $\alpha U$ ditunjukkan oleh puncakpuncak pola difraksi berturut-turut pada sudut $2 \theta$ : $34,78^{\circ} ; 35,6^{\circ} ; 36,14^{\circ}$; 39,52 ; $51,08^{\circ} ; 60,22^{\circ} ; 64,6^{\circ} ; 65,4^{\circ} ; 67,2^{\circ} ; 75,2^{\circ}$ dan $76,8^{\circ}$ dengan indeks Miller (hkl) berturut-turut sebesar 110, 021, 020, 111,
$112,131,023,200,113,042$, dan 004. Fasa $\alpha U$ tersebut mempunyai struktur kristal orthorhombic. Sementara itu, fasa $\delta U$ muncul pada sudut $2 \theta$ berturut-turut : 35,$345 ; 60,015^{\circ}$ dan $64,270^{\circ}$, dengan hkl berturut-turut 021, 131 dan 023. Hasil tersebut bersesuaian dengan percobaan Bruno, dkk[7]. Fasa $\alpha U$ dan $\delta U$ dalam paduan $\mathrm{U}-6 \mathrm{Zr}$ harus dirubah menjadi fasa YU agar stabil di dalam reaktor. 
Pengubahan fasa $\alpha U$ dan $\delta U$ menjadi fasa $\mathrm{YU}$ dilakukan dengan cara memanaskan paduan $\mathrm{U}-6 \mathrm{Zr}$ pada temperatur daerah satu fasa $\mathrm{yU}$ dalam waktu tertentu, selanjutnya dilakukan pendinginan secara cepat. Temperatur satu fasa $\mathrm{YU}$ lebih besar dari $700{ }^{\circ} \mathrm{C}$, karena proses pendinginan cepat maka fasa $\mathrm{YU}$ tidak sempat kembali menjadi fasa $\alpha U$ lagi[8]. Cara lain untuk membuat bahan bakar agar stabil dalam fasa $\mathrm{yU}$ terutama apabila digunakan untuk bahan bakar dimana pada bahan bakar tersebut terdapat matriks Al. Agar interaksi antara bahan bakar dengan matriks Al menjadi stabil maka perlu dilakukan penambahan unsur-unsur tertentu, misalnya unsur $\mathrm{Nb}, \mathrm{Si}, \mathrm{Ti}, \mathrm{Zr}$ ke dalam bahan bakar tersebut ${ }^{[9,10]}$.

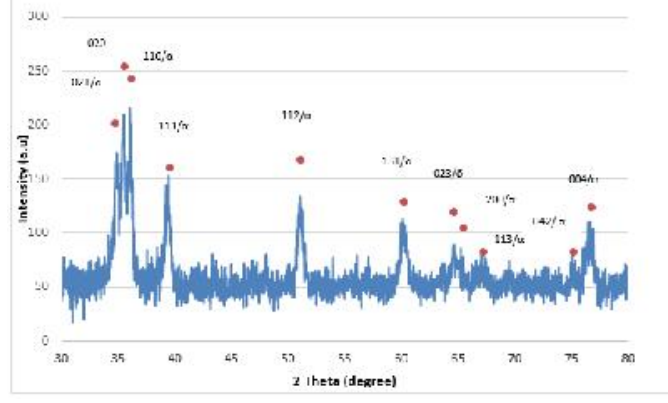

Gambar 1. Pola difraksi U-6Zr

\section{e. Transformasi temperatur}

Hasil analisis termal serbuk U-6Zr berupa termogram DTA yang diukur pada temperatur antara $40{ }^{\circ} \mathrm{C}$ hingga $1000{ }^{\circ} \mathrm{C}$ ditunjukkan pada Gambar 2.

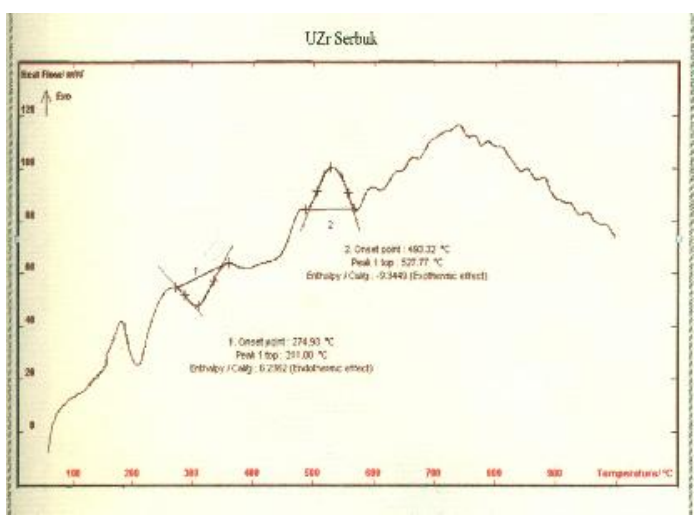

Gambar 2. Transformasi temperatur Serbuk $\mathrm{U}-6 \mathrm{Zr}$
Gambar 2 memperlihatkan terbentuknya dua puncak reaksi termokimia. Puncak pertama pada temperatur $274^{\circ} \mathrm{C}$ hingga $311^{\circ} \mathrm{C}$ dan puncak kedua terjadi pada temperatur $493^{\circ} \mathrm{C}$ hingga $527{ }^{\circ} \mathrm{C}$. Puncak pertama menunjukkan terjadinya reaksi endotermik dengan menyerap panas sebesar $\Delta \mathrm{H}=6,23 \mathrm{cal} / \mathrm{g}$, sedangkan puncak kedua terjadi reaksi termokimia eksotermik dengan mengeluarkan sejumlah panas sebesar $\Delta \mathrm{H}=-9,35 \mathrm{cal} / \mathrm{g}$. Reaksi termokimia eksotermik tersebut terjadi pada temperatur $493^{\circ} \mathrm{C}$ hingga $527^{\circ} \mathrm{C}$ menunjukkan terbentuknya fasa baru yaitu pembentukan fasa $\alpha Z$ r. Fasa $\alpha Z r$ merupakan fasa dimana atom $U$ terlarut padat di dalam atom $\mathrm{Zr}$. Hal ini bersesuaian dengan diagram fasa $\mathrm{Zr}-\mathrm{H}^{[11]}$.

\section{f. Kapasitas panas}

Gambar 3 memperlihatkan hasil pengujian kapasitas panas. Pada temperatur pemanasan dari $34^{\circ} \mathrm{C}$ hingga $75^{\circ} \mathrm{C}$, terlihat terjadinya penurunan nilai kapasitas panas disertai penyerapan panas. Pada temperatur yang lebih tinggi lagi hingga temperatur $437^{\circ} \mathrm{C}$, nilai kapasitas panas bertambah kecil. Kapasitas panas adalah ukuran dari energi panas yang dibutuhkan untuk meningkatkan temperatur suatu benda dengan interval temperatur tertentu. Kapasitas panas merupakan sifat yang luas karena nilainya sebanding dengan jumlah panas dalam suatu bahann ${ }^{[12,13]}$. Kapasitas panas dipengaruhi oleh kandungan unsurunsur dan impuritas unsur yang ada di dalam paduan U-6Zr. Bahan bakar diharapkan mempunyai nilai kapasitas panas yang tinggi agar panas yang terjadi dari pembakaran bahan bakar dapat dipindahkan ke lingkungan sebesarbesarnya. 


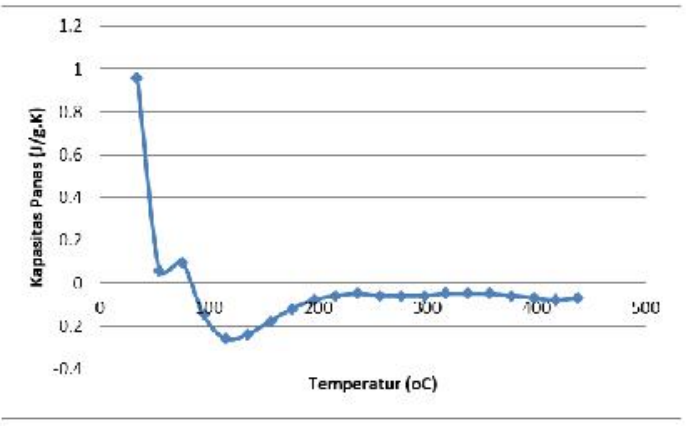

Gambar 3. Kapasitas panas ingot U-6Zr

\section{SIMPULAN}

Hasil pengujian paduan U-6Zr dapat disimpulkan bahwa paduan $\mathrm{U}-6 \mathrm{Zr}$ tersebut bila dilihat dari komposisi kimia dapat digunakan untuk bahan bakar reaktor riset, meskipun beberapa unsur melebihi persyaratan bahan bakar tetapi jumlah unsur secara keseluruhan masih di bawah persyaratan yang diijinkan (jumlah keseluruhan $0,11 \%)$. Hasil pengujian kandungan hidrogen masih ditemukan hidrogen di dalam paduan $\mathrm{U}-6 \mathrm{Zr}$ dalam jumlah sangat kecil $(0,16 \%)$ sehingga tidak mempengaruhi kinerja bahan bakar. Pengujian tranformasi temperatur menunjukkan terjadinya transformasi dari fasa $\alpha U$ menjadi fasa $\alpha Z$ r.

\section{UCAPAN TERIMA KASIH}

Penulis mengucapkan terima kasih kepada Yatno D. A, Slamet Pribadi dan teman-teman yang tidak bias saya sebutkan satu persatu yang telah membantu sehingga hasil percobaan ini dapat dibuat menjadi makalah.

\section{DAFTAR PUSTAKA}

[1].Masrukan, Yanlianastuti, Sutri Indaryati, (2014) "Karakter Termal Serbuk U-6Zr dan U- 10Zr Sebagai Bahan Bakar Reaktor Riset", Jurnal IImiah Daur Bahan Bakar Nuklir" Urania", Volume 20 No 3, Oktober 2014. ISSN 0852 - 4777 : 132- 139. Akreditasi No: 395/ AU2/ P2MI-LIPI/ 04/ 2012.
[2] Balart, Bruzzoni P, Grannowzky M, (2000), "U- Mo Alloy Powder Obtained by Hydride Dehydride Process", Departement Matrial, Commision Nacional de Energia Atomica, Avda. Gral. Paz 1499-1650-San MartinArgentina.

[3] Ki Hwan Kim, Don Bee Lee, Chang kyu Kim, (1997), "Development of Hight Loading U-Mo Alloy Fuel by Centrifugal Atomization", Korea Atomic Energy Institue, Taejon, 305-353 Korea.

[4] Bruno, Claudia, Wilmar, Humberto, (2011), "Method for Preparation Of UZrNb Alloy Powder Passivation", Proceeding of Institue de Pesquisas Energeticase Nucleares, IPEN, Sao Paulo, n.1, p 36-41.

[5] Masrukan, Zuhair, (1998), Pengaruh Kandungan Unsur B Di Dalam Kelongsong Bahan Bakar Nuklir Terhadap Kritikalitas Pertama Reaktor G A Siwabessy, Prosiding Daur Bahan Bakar Nuklir V, Jakarta, November. ISSN : 1410-1998.

[6] MM. Bretcher, J E Mathos, (1996), "Neutronic Performance Of High Density LEU Fuels In Water Moderated And Water Reflected Research Reactor", Argon National Laboratory, 9700 South Cass Avenue, Argonne, Illinois 60439.

[7] Bruno M. Aguiar, Daniel M. Braga, (2007), Methodology of UZrNb Alloy Powder Passivation Obtained by Hydride-Dehydride, Proceeding of International Nuclear Atlantic Conference (INAC), 2007 Santos, SP, Brazil, September 29 to October 5, 2007.

[8] Supardjo, Suwarno, Agoeng K, (2009), "Karakterisasi Paduan U-7\%Mo dan U-7\%Mo-X\%Si ( $x=1,2$ dan 3$)$ Hasil Proses Peleburan Dalam Tungku Busur Listrik", Jurnal IImiah Daur Bahan Bakar Nuklir"Urania", Volume 15 No 4: 171-179. ISSN $0852-4777$.

Akreditasi No: 71/Akred-LIPI / P2MBI / 


\section{$5 / 2007$}

[9] Komar Varela, Gibraudo, Gonzalez, Arico, (2012), "Transformation Behavior of $y U$ Phase Under Continuous Cooling Conditions", Comision Nacional de Energia Atomica, Avenida General Paz 1499, B1650KNA, San Martin, Buenos Aeres-Argentina. Proceeding of 34th International Meeting On Reduced Enrichment for Research and Test Reactors, October, page 14-17.

[10] Supardjo, Agoeng K, Aslina Br. Ginting, (2010). Pembuatan Pelat Elemen Bakar Mini UMo-Al Dengan Densitas Uranium 6 Dan $7 \mathrm{gU} / \mathrm{cm}^{3}$, J. Tek. Bhn. Nukl, Vol. 7 No. 2 Juni 2011: 74 - 156. ISSN No. 1907 - 2635. Akreditasi No.

261/AU1/P2MBI/05/2010
[11] E. Suzek, J.P Abriata, (1990), "The H-Zr System", Centro Atomico Bariloche, Argentina and A.S an-Martin and F.D Manchester, University of Toronto, Bulletin of Alloy Phase Diagram, Vol 11 No 4 tahun 1990.

[12] Byung-Ho Lee, Jin-Sik Cheon, YangHyun Koo, Je-Yong Oh, (2007), "Measurement of the specific heat of Zr-40 wt \%U Metallic Fuel", Journal of Nuclear Materials 360, 315-32.

[13]. Aslina Br.Ginting, M.Husna Al Hasa, Masrukan, (2007). Analisis Sifat Termal Paduan AIFeNi Sebagai Kelongsong Bahan Bakar Reaktor Riset , J.Tek. Bhn. Nukl.Vol. 3 No. 2 Juni, ISSN No. 1907-2635. Akreditasi No. 82/Akred-LIPI/P2MBI/5/2007. Hal. 50. 